\title{
Discussion
}

of

"Interest Rate Dynamics and Monetary Policy Implementation in Switzerland" by Puriya Abbassi, Dieter Nautz and Christian J. Offermanns

\section{Dewet Moser}

The paper essentially confirms the Swiss National Bank' (SNB)'s experience that the three-month Libor has remained manageable, even under the extremely adverse market circumstances of the recent financial crisis. By showing that a central bank can control a rate that is technically out of its reach - i.e. the threemonth interbank money market rate - the paper gives credit to the view that monetary micro management with positive monetary policy value is possible. Targeting a three-month rate rather than a very short-term rate gives the central bank leeway to absorb shocks. This is of particular interest for Switzerland as the great openness of the Swiss economy and the close international ties of its financial sector require an operational framework that allows the SNB to respond promptly and flexibly to changes in financial markets without immediately putting its operational target at risk. If undesired moves occur in the target rate, these can be counteracted by steering the overnight rate in the opposite direction. Furthermore, the paper correctly emphasises the fact that words and deeds are required to manage the Libor in an efficient manner. The joint management of a central bank's words and deeds has become an integral part of what is believed to be good monetary policy practice.

The paper correctly focuses on two distinct features of the SNB's operating procedure. First, the fact that the term of the instrument being targeted is longer than that of the SNB's regular liquidity management transactions (repo transactions). Second, the fact that the policy rate is a market rate and thus subject to factors such as risk premia that are not under the direct control of the SNB.

By means of regressions, and by separating the pre-crisis phase from the crisis phase, the authors reach some plausible findings. The key insights are: a) The one-week repo rate responds to large changes in the risk premium (3M Libor/OIS

1 See Jordan, Thomas J., and Michel Peytrignet (2007), "The Path to Interest Rate Management and Inflation Forecasts", in: Swiss National Bank (ed.), The Swiss National Bank 1907-2007, Zurich: Neue Zürcher Zeitung Publishing, pp. 255-272. 
spread) or deviations between the actual $3 \mathrm{M}$ Libor and the expectation-adjusted target level; b) The $3 \mathrm{M}$ Libor reacts in a measurable way to changes in the term spread, to monetary policy surprises and to deviations between the effective $3 \mathrm{M}$ Libor and the expectation-adjusted target level. Interestingly enough, the analysis of the 3M Libor dynamics shows the best fit in the crisis period when the $3 \mathrm{M}$ Libor fluctuated most significantly - a period in which the policy relevance and the manageability of the $3 \mathrm{M}$ Libor was seriously questioned by academics and practitioners. Overall, the empirical part of the paper supports the view that words and deeds - combined with some patience - can be effective in managing the $3 \mathrm{M}$ Libor.

However, the empirical analysis is not taking into account any unconventional measures introduced by the SNB and repo rates hitting the zero lower bound during the crisis period. This might be a reason why the statistical results of the repo rate dynamics are less convincing for the crisis phase. By late 2008, the SNB had lowered the repo rate to the zero lower bound, leaving no more room for further repo rate reductions. Subsequently, the SNB exerted influence on the Swiss franc money market through the amount of excess reserves it injected into the market, and also by resorting to unconventional measures. These unconventional measures included, in particular, an enormous volume of euro/Swiss franc swap operations, sizable foreign currency purchases in the form of unsterilised foreign exchange interventions and outright purchases of Swiss franc denominated bonds. All these measures were exceptional in terms of frequency and magnitude but remained within the monetary policy framework of the SNB. Further work taking account of these unconventional measures will be needed.

In conclusion, the paper provides a valuable case study with some relevant insights that should be of benefit beyond the Swiss case. It confirms that the design of the monetary policy operating procedure does matter. Consequently, academics and central bankers should continue exploring this area. 